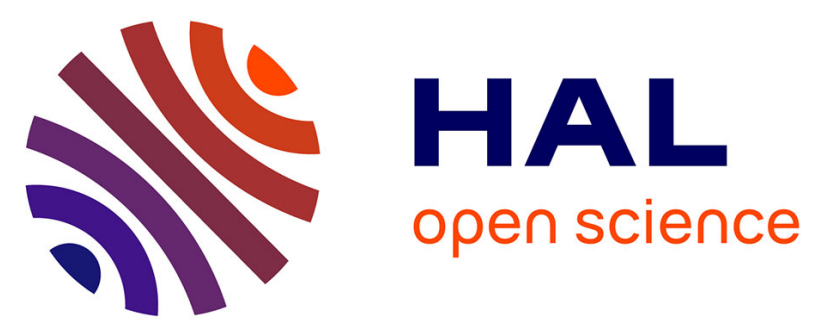

\title{
Structural and nuclear characterizations of defects created by noble gas implantation in silicon oxide
}

H. Assaf, E. Ntsoenzok, M.-F. Barthe, M.-O. Ruault, T. Sauvage, S. Ashok

\section{To cite this version:}

H. Assaf, E. Ntsoenzok, M.-F. Barthe, M.-O. Ruault, T. Sauvage, et al.. Structural and nuclear characterizations of defects created by noble gas implantation in silicon oxide. E-MRS IUMRS ICEM 2006 Spring Meeting - Symposium U: Si-based Materials for Advanced Microelectronic Devices: Synthesis, Defects and Diffusion, May 2006, Nice, France. pp.222-226, 10.1016/j.nimb.2006.10.042 . in2p300115973

\section{HAL Id: in2p3-00115973 \\ https://hal.in2p3.fr/in2p3-00115973}

Submitted on 24 Nov 2006

HAL is a multi-disciplinary open access archive for the deposit and dissemination of scientific research documents, whether they are published or not. The documents may come from teaching and research institutions in France or abroad, or from public or private research centers.
L'archive ouverte pluridisciplinaire HAL, est destinée au dépôt et à la diffusion de documents scientifiques de niveau recherche, publiés ou non, émanant des établissements d'enseignement et de recherche français ou étrangers, des laboratoires publics ou privés. 


\title{
Structural and nuclear characterizations of defects created by noble gas implantation in silicon oxide
}

H. Assaf ${ }^{1}$, E. Ntsoenzok ${ }^{1,2}$, M.-F. Barthe ${ }^{1}$, M.-O. Ruault ${ }^{3}$, T. Sauvage ${ }^{1}$, S. Ashok $^{4}$.

${ }^{1}$ CERI-CNRS, 3A, rue de la Férollerie, 45071 Orléans, France.

${ }^{2}$ LESI, University of Orleans, 21 rue de Loigny la bataille, 28000 Chartres, France

${ }^{3}$ CSNSM, CNRS-IN2P3, Batiment 108-F-91405 Orsay, France.

${ }^{4}$ Department of Engineering Science, the Pennsylvania State University, 212 Earth and

Engineering Science Building, University Park, PA 16802, USA.

\begin{abstract}
Thermally grown silicon oxide layer was implanted at room temperature with $300 \mathrm{keV} \mathrm{Xe} \mathrm{at}$ fluences ranging from 0.5 to $5 \times 10^{16} \mathrm{Xe} / \mathrm{cm}^{2}$. Bubbles created after Xe-implantation provided a low-k silicon oxide that has potential use as a dielectric material for interconnects in

Si integrated circuits. Transmission Electron Microscopy (TEM), Rutherford Backscattering Spectrometry (RBS) and Positron Annihilation Spectroscopy (PAS) were used to provide a comprehensive characterization of defects (bubbles, vacancy, gas atoms and other types of defects) created by $\mathrm{Xe}$ implantation in $\mathrm{SiO}_{2}$ layer. These measurements suggest that the bubbles observed with TEM for all fluences were a consequence of the interaction between $\mathrm{Xe}$ and vacancies $(\mathrm{V})$, with $\mathrm{V}_{\mathrm{n}} \mathrm{Xe}_{\mathrm{m}}$ complexes created in the zone where $\mathrm{V}$ and $\mathrm{Xe}$ profiles overlap. Negatively charged defects such as $\left(\mathrm{Si}^{-} \mathrm{O}^{-}, \mathrm{Si}-\mathrm{O}-\mathrm{O}^{-}\right.$and $\left.\mathrm{O}_{2}{ }^{-}\right)$are also created after implantation.
\end{abstract}




\section{Introduction}

The speed of ULSI circuits is becoming dominated less by the speed of the individual devices but more by the RC time constant of the layers of interconnects tying the devices together ${ }^{1}$. To date $\mathrm{SiO}_{2}$ has been the dielectric material of choice in this application, but because of its relatively high permittivity $(\mathrm{k} \sim 4)$, it contributes to a large capacitance between the metal layers and thus a large $\mathrm{RC}$ delay to the circuit ${ }^{2}$. By reducing the permittivity of $\mathrm{SiO}_{2}$, the $\mathrm{RC}$ delay might be reduced leading to faster performances ${ }^{3}$. The implantation of heavy noble gas such as Xe in silicon oxide was recently used for decreasing its permittivity and thus offering prospects for a new technique to produce an ultra low-k dielectric (ULK) with $\mathrm{k} \leq 1.5^{4,5}$. This $\mathrm{k}$ reduction is due to the bubble formation in the silicon oxide. No model has yet been proposed to study the formation and growth mechanisms of bubbles in $\mathrm{SiO}_{2}$ matrix, while these mechanisms are quite well known in metals ${ }^{6}$ and semiconductors ${ }^{7}$.

This paper deals with an extensive characterization of defects (vacancy or negatively charged defects, bubbles and gas atoms) induced by Xe-implantation in silicon oxide. For this purpose, TEM, RBS and PAS techniques were used.

\section{Experimental procedure}

A $2.3 \mu \mathrm{m}$ silicon oxide was grown by heating n-type silicon wafers at $1100^{\circ} \mathrm{C}$ in air. Some of these $\mathrm{SiO}_{2} / \mathrm{Si}$ structures were implanted, at room temperature, by $300 \mathrm{keV} \mathrm{Xe}$ at various fluences: $0.5,1,3.5$ and $5 \times 10^{16} / \mathrm{cm}^{2}$. Such an energy results in Xe implantation at a depth of $125 \mathrm{~nm}$ as simulated by TRIM. Bubble formation after Xe implantation in silicon oxide was characterized by cross-sectional transmission electron microscopy (XTEM) using a Philips CM12 microscope. 
Rutherford backscattering spectrometry (RBS) was used to obtain the Xe distribution in silicon oxide. RBS measurements were performed using a $2 \mathrm{MeV}^{4} \mathrm{He}$ beam provided by a 3.5MeV Van de Graaff accelerator.

Positron annihilation spectroscopy (PAS) was performed in order to study the defects induced by Xe-implantation using a monoenergetic positron beam with energies tuneable over 0.5$25 \mathrm{keV}^{8}$. In this energy range, the positron mean implantation depth in $\mathrm{SiO}_{2}$ calculated by using the equation $\mathrm{Z}(\mathrm{E})[\mathrm{nm}]=12.75 \times \mathrm{E}^{1.7}[\mathrm{keV}]$ with the same parameters as for $\mathrm{Si}^{9}$ varies from 40 to $3000 \mathrm{~nm}$. After implantation and thermalization, positron diffuses through the solid until it either annihilates with an electron in a delocalized state or is trapped at a defect. Free annihilation results in the emission of two $511 \mathrm{keV} \pm \Delta \mathrm{E}$ photons where $\Delta \mathrm{E}$ is proportional to the momentum of the electron-positron annihilated pairs (Doppler broadening). The two-photon annihilation events are detected at room temperature with a Ge detector. Approximately $10^{6}$ events were collected in the peak at each positron energy value. The various annihilation processes can be distinguished by analyzing the shape of the photopeak. The shape is defined by the $\mathrm{S}$ (hape) and W(ing) parameters. The S parameter is defined as the relative contribution of the central part of the peak in the energy window 511[$0.66 ;+0.66] \mathrm{keV}$ and is the fraction of annihilation with low momentum electrons, mainly the valence electrons. The $\mathrm{W}$ parameter is defined by the relative contributions in the wings of the peak in the energy windows $511[-6.64 ;-2.57] \mathrm{keV}$ and $511[+2.57 ;+6.64] \mathrm{keV}$ and is the fraction of annihilation with high momentum electrons, mainly the core electrons. The $\mathrm{S}$ and W distribution as a function of depth are determined by the consistent fitting of the $S(E)$ and $\mathrm{W}(\mathrm{E})$ data measured as a function of positron energy using a modified version of the VEPFIT $\operatorname{program}^{10}$. The sample is modelled as a sequence of $\mathrm{n}$ homogeneous layers with the annihilation characteristics $\mathrm{S}_{\mathrm{i}}, \mathrm{W}_{\mathrm{i}}$ and the positron effective diffusion length $\mathrm{L}_{\mathrm{i}}^{+}$specific to the layer i. In our case, $\mathrm{S}(\mathrm{E})$ and $\mathrm{W}(\mathrm{E})$ evolutions are fitted for energy higher than $1.5 \mathrm{keV}$. The 
data below $1.5 \mathrm{keV}$ are discarded because in this range the positrons migration is not only due to a diffusion process.

\section{Results and discussion}

Fig. 1 -a presents the typical XTEM images obtained in $2.3 \mu \mathrm{m}$ silicon oxide by $300 \mathrm{keV} \mathrm{Xe}$ ion implantation at different fluences: $0.5,1,3.5$, and $5 \times 10^{16} / \mathrm{cm}^{2}$. Extended defects can be observed and they can be attributed to bubbles/cavities induced in $\mathrm{SiO}_{2}$ by implantation. Their size distributions show that for the sample implanted at 0.5 and $1 \times 10^{16} / \mathrm{cm}^{2}$ fluences the majority of bubbles has a mean diameter less than $6 \mathrm{~nm}$. The mean diameter increases with the fluence. At 3.5 and $5 \times 10^{16} / \mathrm{cm}^{2}$, bubbles present a wider range of diameters - from $\sim 6 \mathrm{~nm}$ up to 40nm. The thickness of the bubble/cavity band increases with the implanted fluence from $65 \mathrm{~nm}$ for the lowest fluence $\left(0.5 \times 10^{16} \mathrm{Xe} / \mathrm{cm}^{2}\right)$ to $160 \mathrm{~nm}$ for the highest one $\left(5 \times 10^{16} \mathrm{Xe} / \mathrm{cm}^{2}\right)$. Fig.2-a illustrates the evolution of Xe profiles with the Xe fluence in silicon oxide as measured by RBS technique. For the fluences of 0.5 and $1 \times 10^{16} \mathrm{Xe} / \mathrm{cm}^{2}$, the Xe distribution has a gaussian profile centered at $116 \mathrm{~nm}$ depth while for the higher fluences of 3.5 and $5 \times 10^{16} \mathrm{Xe} / \mathrm{cm}^{2}, \mathrm{Xe}$ profiles consist of a main peak with two shoulders on both sides. The main peak is located at the depth of 95 and $90 \mathrm{~nm}$ for the fluence of 3.5 and $5 \times 10^{16} \mathrm{Xe} / \mathrm{cm}^{2}$ respectively. The region where $\mathrm{Xe}$ is detected corresponds to the largest bubble zone. It suggests that $\mathrm{Xe}$ is predominantly located inside the bubbles. According to TRIM simulations, displacement per atom (dpa) [called also "vacancy" (V) if the displaced atom does not return to its initial position after implantation] and Xe peaks are located at depths of $85 \mathrm{~nm}$ and $125 \mathrm{~nm}$ respectively, as shown in Fig. 2-b. We can then conclude that bubbles are formed between these two zones, probably in the zone of overlapping of $\mathrm{V}$ and $\mathrm{Xe}$ where the most stable $\mathrm{V}_{\mathrm{n}} \mathrm{Xe} \mathrm{e}_{\mathrm{m}}$ complexes are created. Since, the fluence is very large, overlapping is expected as seen in fig.2-b. 
In fig. 3, the low and high momentum annihilation fractions $\mathrm{S}$ and $\mathrm{W}$ values are plotted as a function of the positron implantation energy $\mathrm{E}\left(\mathrm{S}(\mathrm{E})\right.$ and $\mathrm{W}(\mathrm{E})$ ) for the $\mathrm{SiO}_{2} / \mathrm{Si}$ structures before and after Xe implantation. Before implantation (reference sample), S(E) increases with positron energy first rapidly up to $5 \mathrm{keV}$ where it reaches a plateau value at about $15 \mathrm{keV}$ and then $\mathrm{S}(\mathrm{E})$ increases again more slightly up to $25 \mathrm{keV}$. W(E) has the reversible evolution of $\mathrm{S}(\mathrm{E})$ but from the energy of $15 \mathrm{keV}$, its decrease is more significant than the increase of $\mathrm{S}(\mathrm{E})$. Using the VEPFIT program, the evolution of $S(E)$ and $W(E)$ can be fitted with a model of two homogeneous layers: Layer 1 the virgin $\mathrm{SiO}_{2}$ layer with the annihilation characteristics $\left(\mathrm{S}_{\mathrm{SiO} 2} \sim 0,471(1), \quad \mathrm{W}_{\left.\mathrm{SiO}_{2} \sim 0,0491(1)\right)}\right.$ and layer 2 the virgin silicon substrate with the annihilation characteristics $\left(\mathrm{S}_{\mathrm{Si}} \sim 0,472(1), \mathrm{W}_{\mathrm{Si}} \sim 0,0275(1)\right)$. The effective diffusion length $\left(\mathrm{L}^{+}\right)$ of positrons is about $36 \mathrm{~nm}$ for $\mathrm{SiO}_{2}$ (layer 1) and $230 \mathrm{~nm}$ for $\mathrm{Si}$ (layer 2). $\mathrm{L}^{+}$is short in the $\mathrm{SiO}_{2}$ layer, indicating that positrons are trapped in this virgin $\mathrm{SiO}_{2}$ layer.

After Xe-implantation, $\mathrm{S}(\mathrm{E})$ decreases in the region of positron energy between 0.5 and $5 / 6 \mathrm{keV}$ depending on the implanted fluence. At this energy, the mean implantation depth of positrons is about $270 \mathrm{~nm}$. W(E) has the reverse behaviour. Then $\mathrm{S}(\mathrm{E})$ increases (and $\mathrm{W}(\mathrm{E})$ decreases) with positron implantation energy up to $25 \mathrm{keV}$, regardless of the implanted fluence. Using VEPFIT program, $\mathrm{S}(\mathrm{E})$ and $\mathrm{W}(\mathrm{E})$ curves can be fitted with a mode describing the sample as four homogenous layers. From the surface positron probe, first two are damaged $\mathrm{SiO}_{2}$ layers (1 and 2) and then the third and fourth layers correspond respectively to the undamaged $\mathrm{SiO}_{2}$ layer and $\mathrm{Si}$ substrate. The $(\mathrm{S}, \mathrm{W})$ values obtained for the layer 3 and 4 are equal to the annihilation characteristics of the virgin $\mathrm{SiO}_{2}\left(\mathrm{~S}_{\mathrm{SiO} 2}, \mathrm{~W}_{\mathrm{SiO} 2}\right)$ and of the $\mathrm{Si}$ substrate $\left(\mathrm{S}_{\mathrm{Si}}, \mathrm{W}_{\mathrm{Si}}\right)$, respectively, irrespective of the implanted fluences. Parameters characterizing the damaged $\mathrm{SiO}_{2}$ (layers 1 and 2) are shown in the Table I. The $\mathrm{S}_{1}$ low momentum fraction increases (as $\mathrm{W}_{1}$ high momentum fraction decreases) in layer 1 and $\mathrm{S}_{2}$ decreases $\left(\mathrm{W}_{2}\right.$ increases $)$ in layer 2 when the fluence increases. The values of $S_{1}$ and $S_{2}$ 
determined in the two damaged (layers 1 and 2) remain lower than $\mathrm{S}_{\mathrm{SiO} 2}$ and the values of $\mathrm{W}_{1}$ and $\mathrm{W}_{2}$ are largely higher than $\mathrm{W}_{\mathrm{SiO} 2}$, whatever the implanted fluence. It indicates that the nature or the distribution of the annihilation states detected by the positrons change after implantations in the layers 1 and 2 . The effective diffusion length of positron $\left(\mathrm{L}^{+}\right)$is shorter than the value obtained in the virgin $\mathrm{SiO}_{2}$ layer, highlighting the existence of defects which trap positron and limit their diffusion into the $\mathrm{SiO}_{2}$ up to the surface. Two types of point defects have already been identified (see references for details) ${ }^{11}$ to be created in silicon oxide. Some of these defects can trap positrons leading to the $\mathrm{S}$ and $\mathrm{L}^{+}$evolution as presented in Table II. When the defect is an open-volume type like the vacancy, $\mathrm{S}$ is expected to increase. In these $\mathrm{SiO}_{2}$ layers, $\mathrm{Si}$ and $\mathrm{O}$ atoms can be displaced during implantation, leading to the formation of different vacancy defects like oxygen, or silicon monovacancies or defects with larger open volume. As reported by Richard et $\mathrm{al}^{12}$, the stable vacancy defect created by implantation in $\mathrm{SiO}_{2}$ is the neutral oxygen vacancies due to its very low formation energy; the Si-vacancy is not very stable after implantation. It suggests that positrons could be trapped in these neutral oxygen vacancies or in defects with larger open volume leading to the increase of the low momentum fraction $\mathrm{S}$ after implantation. The $\mathrm{S}$ decrease is expected when positrons are trapped at acceptor and non vacancy-like defects that can be assimilated to "negative ions" such as $\mathrm{O}_{2}^{-}$(dissolved oxygen molecules), $\equiv \mathrm{Si}-\mathrm{O}^{-}$(NBOHC centers), $\equiv S i-O-O^{-}($POR centers $\left.)\right)^{13,14}$. According to our PAS results, we can conclude that the dominant defects detected after Xe-implantation in silicon oxide are the "negative ions". We cannot specify exactly which defect (dissolved oxygen molecules, NBOHC or POR centers) leads to the reduction of $\mathrm{S}$ and $\mathrm{L}^{+}$. Fujinami et al ${ }^{13}$ proposed that "NBOHC centers" trap positrons in boron-implanted $\mathrm{SiO}_{2}$, while Knights et al ${ }^{14}$ concluded from detailed detection by using EPR and PAS techniques that dissolved oxygen, NBOHC or POR centers could be the defects leading to the $\mathrm{S}$ decrease in $\mathrm{SiO}_{2}$ implanted with $\mathrm{Ge}$ ions. 
In Xe implanted samples we have observed that $S_{1}$ values determined in layer 1 are higher than the ones obtained in layer 2; moreover $S_{1}$ increases when implantation fluence increases (see Table I). This suggests that, in this layer, vacancy-defects (oxygen vacancies or defects with larger open volume) also exist and their concentration or their size increases with the fluence. The thickness of this layer 1 depends on the Xe fluence - it is $140 \mathrm{~nm}$ for the lowest fluence and increases to $200 \mathrm{~nm}$ for the highest.

Comparing PAS results with TEM and RBS results, we can conclude that layer(1) corresponds to the bubble region where the Xe has maximum concentration. In this layer, vacancies $\left(\mathrm{V}_{\mathrm{n}}\right.$, detected by PAS) can interact with Xe atoms (detected by RBS) and create the $\mathrm{V}_{\mathrm{n}} \mathrm{Xe}_{\mathrm{m}}$ complexes that are visible in XTEM images as bubbles. The layer 2 is located deeper than the layer 1 . In this layer S decreases slightly with the Xe fluence, suggesting that the concentration of the negatively charged defects increases with the fluence. The maximum width of defect layer is larger than the one calculated by TRIM (approximately $230 \mathrm{~nm}$ ), and ranges from $360 \mathrm{~nm}$ for the lowest fluence and $>385 \mathrm{~nm}$ for the highest fluence. Layer2 is located deeper than the implanted region projected by TRIM, hence we suggest that the negatively charged defects detected in this layer are more probably formed by ejection of interstitial oxygen from the implanted region (layer1) to layer2. Interstitial oxygen atoms ejected in this layer can exist as dissolved oxygen molecules $\left(\mathrm{O}_{2}^{-}\right)$or if they have a sufficient energy, they can break Si-O-Si bonds in the matrix and form NBOHC and POR centers deeper than the Xe range.

\section{Summary}

The following major results can be underlined:

- Xe implantation in $\mathrm{SiO}_{2}$ induces bubbles whose size and distribution evolve with the $\mathrm{Xe}$ fluence. 
- Xe distribution in silicon oxide is fluence-dependent. A gaussian profile is obtained for the lowest fluences $\left(0.5\right.$ and $\left.1 \times 10^{16} \mathrm{Xe} / \mathrm{cm}^{2}\right)$ while for the highest fluences (3.5 and $5 \times 10^{16} \mathrm{Xe} / \mathrm{cm}^{2}$ ) a main peak with two shoulders on both sides is observed.

- Positron Annihilation Spectroscopy (PAS) shows that the dominant defects detected in silicon oxide after implantation are the negatively charged defects $\left(\mathrm{O}_{2}{ }^{-}\right.$, and/ or NBOHC and/or POR centers). These defects are formed in the whole of implanted region and detected at depths greater than $385 \mathrm{~nm}$.

- Vacancy defects (oxygen vacancies or defects with large open volume) were also detected by PAS technique. These defects are localized in the bubble region as observed by TEM. The concentration and the size of these defects increases with the implanted fluence. In this region, RBS results shows that the concentration of $\mathrm{Xe}$ atoms is maximum, suggesting that interactions of the Xe atoms and vacancies in this region lead to the formation of $\mathrm{Xe}_{\mathrm{n}} \mathrm{V}_{\mathrm{m}}$ complexes that can be the precursors to the bubbles. 


\section{References}

1- International Technology Roadmap for Semiconductors 2003, Semiconductor Industry Association, www.itrs.net.

2- J. Xu, J. Moxom, S. Yang, and R. Suzuki, T. Ohdaira, Appl. Surf. Sci. 194, (2002), 189.

3- Z.-C. Wu, Z.W. Shiung, C.C. Chiang, W.H. Wu, M.C. Chen, S.M. Jeng, W. Chang, P.F. Chou, S.M. Jang, C.H. Yu, M.S. Liang, J. Electrochem. Soc. 148, (2002), 115.

4- H. Assaf, E. Ntsoenzok, M. -O. Ruault, O. Kaitasov, Solid State Phenom. 108/109, (2005), 291.

5- E. Ntsoenzok, H. Assaf, M.-O. Ruault, Semiconductor Defect Engineering - Materials, Synthetic Structures and Devices, MRS Vol. 864, San Francisco, CA, edited by S. Ashok, J. Chevallier, B.L. Sopori, M. Tabe and P. Kiesel (Materials Research Society, Warrendale, PA) (2006), p. 327.

6- C.H. Zhang, K.Q. Chen, Y.S. Wang, J.G. Sun, D.Y. Shen, Journal of Nuclear Materials 245, (1997), 210.

7- S. Godey, T. Sauvage, E. Ntsoenzok, H. Erramli, M.F. Beaufort, J.F. Barbot, B. Leroy, J. Appl. Phys. 87, (1999), 2158.

8- P. Desgardin, L. Liszkay, M-F Barthe, L. Henry, J. Briaud, M. Saillard, L. Lepolotec, C. Corbel, G. Blondiaux, A. Colder, P. Marie and M. Levalois, Materials Science Forum 363365, (2001), 523.

9- A. Van Veen, H. Schut, J. De Vries, R.A. Hakvoort, and M.R. Ijpma, AIP Conf. Proc. 218, (1990), 171.

10- E. Soininen, J. Mäkinen, D. Beyer and P. Hautojärvi, Phys. Rev. B 46, (1992), 13104.

11- C.H. de Novin, A. Barbu, Solid State Phenom. 30\& 31, (1993), 227.

12- N. Richard, L. Martin-Samos, G. Roma, Y. Limoge, J-P. Crocombette, J. of Noncrystalline Solids, 351, (2005), 1825.

13- M. Fujinami, N.B. Chilton, Appl. Phys; Lett. 62, (1993), 1131.

14- A.P. Knights, L.B. Allard, J.L. Brebner, P.J. Simpson, Nucl. Instr. and Meth. B 127-128, (1997), 86. 


\begin{tabular}{|c|c|c|c|c|c|}
\hline & $\begin{array}{l}\text { Fluences } \\
\left(\mathrm{Xe} / \mathrm{cm}^{2}\right)\end{array}$ & $5 \times 10^{15}$ & $1 \times 10^{16}$ & $3,5 \times 10^{16}$ & $5 \times 10^{16}$ \\
\hline \multirow{4}{*}{ 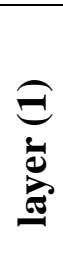 } & thickness (nm) & $140(3)$ & $149(3)$ & 192(5) & $200(5)$ \\
\hline & $S$ & $0.429(0.8)$ & $0.431(1)$ & $0.442(1)$ & $0.449(1)$ \\
\hline & $\mathrm{W}$ & $0,0572(1)$ & $0,0564(0.6)$ & $0,0528(1)$ & $0.0505(1)$ \\
\hline & $\mathrm{L}^{+}(\mathrm{nm})$ & $7(1)$ & $3(0.5)$ & $2.5(0.5)$ & $2.5(0.5)$ \\
\hline \multirow{4}{*}{ 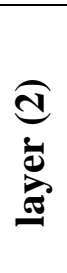 } & thickness (nm) & $220(1)$ & $211(1)$ & $184(1)$ & $185(1)$ \\
\hline & S & $0.409(1)$ & $0,408(1)$ & $0,405(1)$ & $0,403(1)$ \\
\hline & $\mathrm{W}$ & $0.0619(1)$ & $0.0621(1)$ & $0.0628(1)$ & $0.0632(1)$ \\
\hline & $\mathrm{L}^{+}(\mathrm{nm})$ & $9(1)$ & $9(1)$ & $9(1)$ & $9(1)$ \\
\hline
\end{tabular}

TableI: Positron annihilation parameters $\left(\mathrm{S}, \mathrm{W}\right.$ and $\left.\mathrm{L}^{+}\right)$and thickness of damaged layers formed after Xe implantation with different fluences in silicon oxide layer as determined by fitting the $\mathrm{S}(\mathrm{E})$ and $\mathrm{W}(\mathrm{E})$ curves with a model of homogeneous layers using a modified version of VEPFIT $^{10}$. 


\begin{tabular}{|c|c|c|}
\hline name & structures & Evolution of positron characteristics \\
\hline vacancy defects & $\begin{array}{l}\equiv S i-S i \equiv \text { and } \\
\equiv S i-O-O-S i \equiv\end{array}$ & $\mathrm{S} \nearrow, \mathrm{W} \backslash, \mathrm{L}^{+} \searrow$ \\
\hline Dissolved oxygen & $\mathrm{O}_{2}^{-}$ & $\mathrm{S} \searrow, W \nearrow, L^{+} \searrow$ \\
\hline E' centers & $\equiv S i^{+}$ & - \\
\hline NBOHC centers & $\equiv S i-O^{-}$ & $\mathrm{S} \searrow, \mathrm{W} \nearrow, \mathrm{L}+\searrow$ \\
\hline Peroxy radical & $\equiv S i-O-O^{-}$ & $\mathrm{S} \searrow, \mathrm{W} \nearrow, \mathrm{L}+\searrow$ \\
\hline
\end{tabular}

TableII: Defects created in silicon oxide after implantation from published literature and expected evolution of the characteristics of the positrons $\mathrm{S}, \mathrm{W}$ and $\mathrm{L}^{+}$when they are trapped by these defects . 


\section{Figure captions}

Figure 1: XTEM images of silicon oxide layers implanted with $300 \mathrm{keV} \mathrm{Xe}$ at different fluences: $0.5 \times 10^{16} \mathrm{Xe} / \mathrm{cm}^{2}, 1 \times 10^{16} \mathrm{Xe} / \mathrm{cm}^{2}, 3.5 \times 10^{16} \mathrm{Xe} / \mathrm{cm}^{2}$ and $5 \times 10^{16} \mathrm{Xe} / \mathrm{cm}^{2}$.

Figure 2: (a) Evolution of Xe depth profiles obtained by $\mathrm{RBS}$ in $\mathrm{SiO}_{2}$ implanted with $\mathrm{Xe}$ at different fluences and (b) displacement per atom (dpa) and Xe depth profiles in $\mathrm{SiO}_{2}$ implanted with $300 \mathrm{keV} \mathrm{Xe}$ at $5 \times 10^{16} \mathrm{Xe} / \mathrm{cm}^{2}$ as calculated by using TRIM program.

Figure 3: Evolution of the low and high momentum annihilation fractions $(\mathrm{S}, \mathrm{W})$ as a function of positron implantation energy in $\mathrm{SiO}_{2} / \mathrm{Si}$ structures before and after $\mathrm{Xe}$ implantation at different fluences : $0.5 \times 10^{16} \mathrm{Xe} / \mathrm{cm}^{2}, 1 \times 10^{16} \mathrm{Xe} / \mathrm{cm}^{2}, 3.5 \times 10^{16} \mathrm{Xe} / \mathrm{cm}^{2}$ and $5 \times 10^{16} \mathrm{Xe} / \mathrm{cm}^{2}$. The solids lines are a fit of the $(\mathrm{S}, \mathrm{W})$ curves with a model of homogeneous layers using a modified version of VEPFIT ${ }^{10}$. The mean implantation depth in $\mathrm{SiO}_{2}$ is calculated as $\mathrm{z}(\mathrm{E})$ $[\mathrm{nm}]=12.75 \times \mathrm{E}^{1.7}[\mathrm{keV}]^{9}$. 

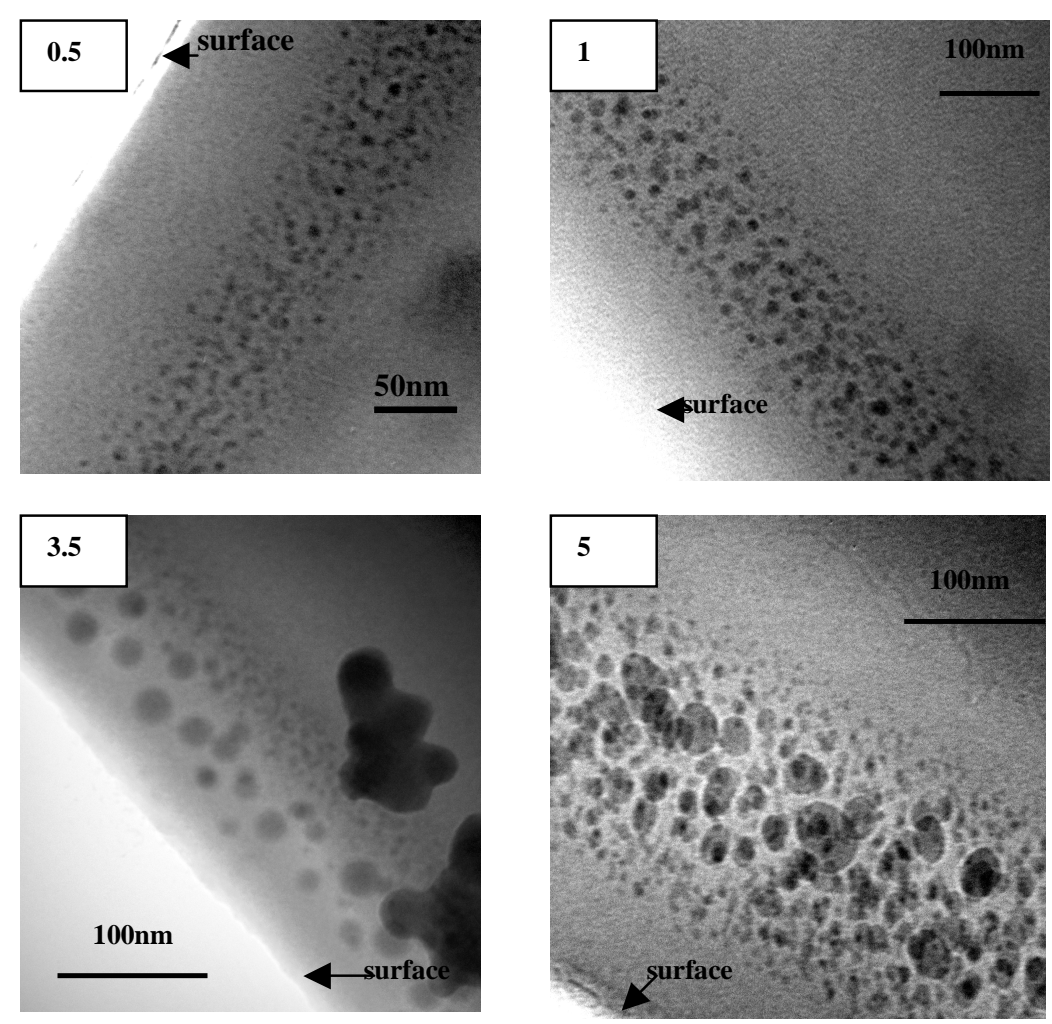

FIG.1 

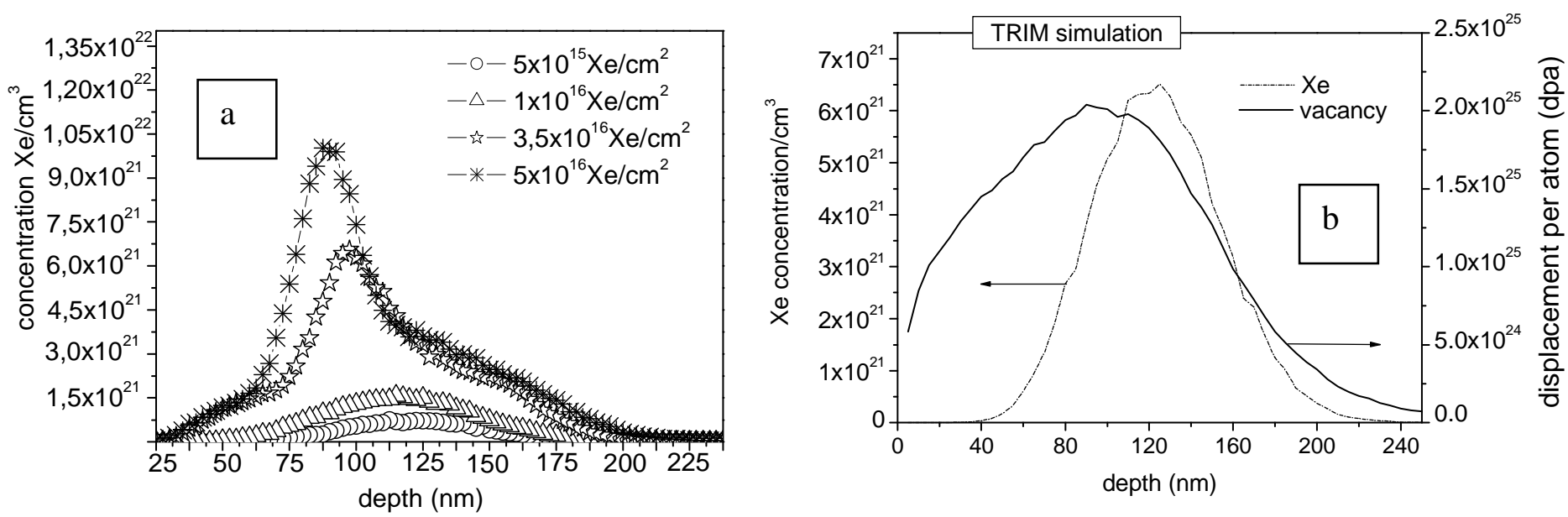

FIG.2 


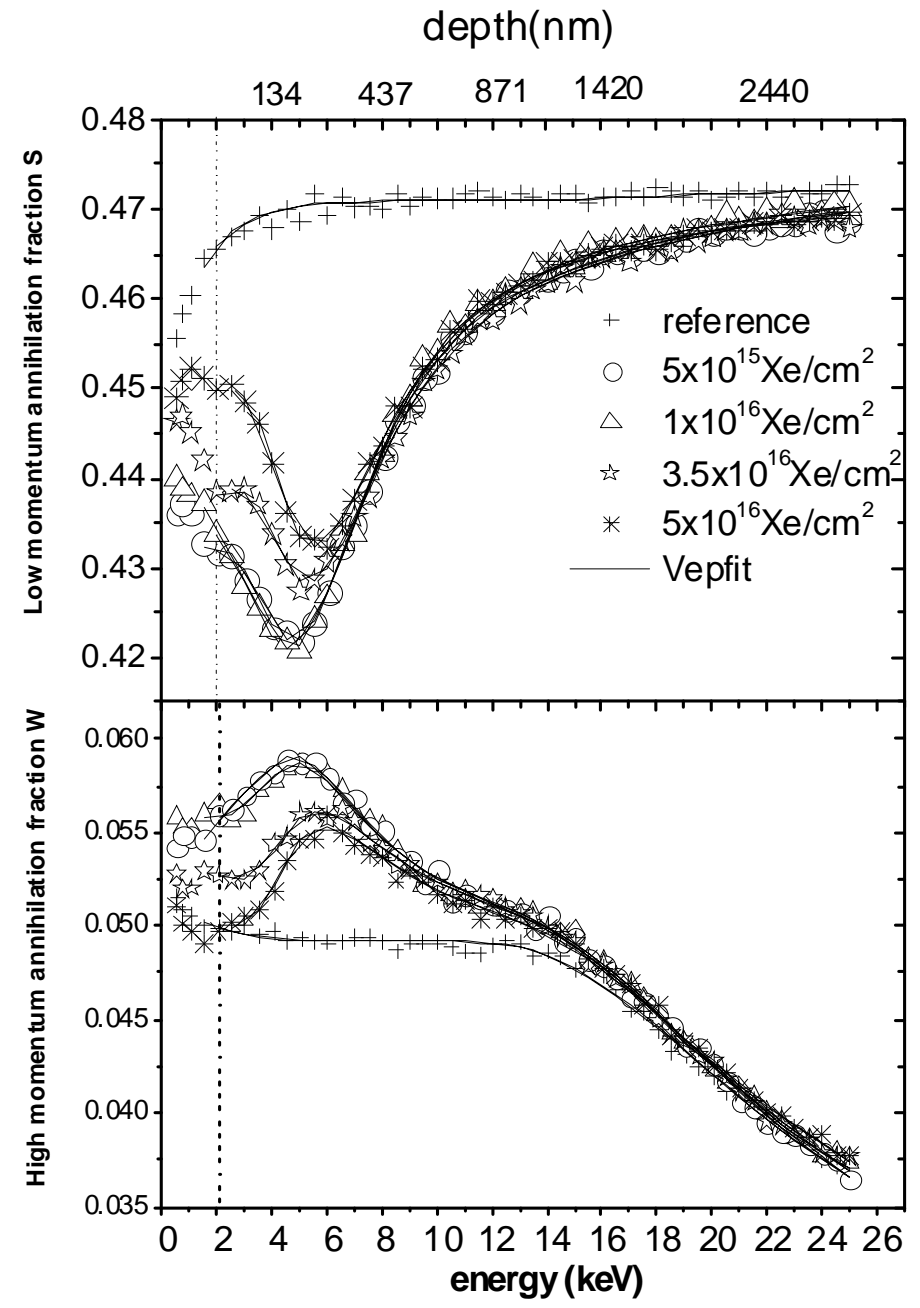

FIG.3 